\title{
SIVAS ARKEOLOJI MÜZESINDE BULUNAN ÇARPANA DOKUMALAR
}

\author{
TABLET WEAVING IN THE SIVAS ARCHEOLOGY MUSEUM
}

\author{
Şirin Karaman*, M. Fatih Çakmaktepe**
}

\section{Öz}

Orta Asya'dan beri devam eden gelenekli sanatlarımızın sürdürülebilir olmalarında müzeler iyi birer kaynak niteliği taşımaktadırlar. Bazen kaybolduğu düşünülen bir sanatın müzelerde korunmuş olması ile yeniden canlandırılması sağlanmaktadır. Dokuma kültüründe; tekniği ve kullanım açısından farklı özelliklere sahip çarpanalar (kolan dokumlar) son dönemlerde diğer el dokumalarına kıyasla daha fazla unutulmaya yüz tutmuştur. Oysaki konargöçer yaşayan Türk kültüründe işlevselliği ön planda olan çarpanalar, taşımacılık ve bağlamada sağlamlığıyla geniş bir kullanım alanına sahipken günümüzde neredeyse kullanılmamaktadır. Değişik genişliklere sahip olan üzeri motiflerle bezeli çarpanalar birer kültürel miras niteliği taşımaktadır. Bu çalışma ile bünyesinde birçok kıymetli eser bulunduran Sivas Arkeoloji Müzesi'nde yer alan çarpanaları gün yüzüne çıkarmak ve tekrar dokunmalarını sağlayarak günlük kullanımda veya dekoratif süs eşyası gibi farklı alanlarda kullanılması amaçlanmıştır.

Anahtar Kelimeler: El Sanatları, Dokuma, Müze, Çarpana, Sivas.

\begin{abstract}
Museums are a good source for the sustainability of our traditional arts, which have been continuing since Central Asia. An art that is sometimes thought to be lost is revived by preserving it in museums. In weaving culture; Tablet weaving, which have different features in terms of technique and usage, have been forgotten more recently compared to other hand weavings. However, the tablet weaving, whose functionality is at the forefront in the nomadic Turkish culture, have a wide area of use with their robustness in transportation and mooring, but they are almost not used today. The tablet weaving, which have different widths and are decorated with motifs, have the characteristics of cultural heritage. With this study, it was designed to be used in different areas such as decorative ornaments to unearth the tablet weaving in the Sivas Archeology Museum, which contains many valuable works, and to make them touch again.
\end{abstract}

Keywords: Handcraft, Weaving, Museum, Tablet Weaving, Sivas.

Araştırma Makalesi // Başvuru tarihi: 16.08.2021 - Kabul tarihi: 20.12.2021

* Dr. Öğr. Üyesi, Sivas Cumhuriyet Üniversitesi, Sivas Meslek Yüksekokulu, El Sanatları Bölümü, sahan@cumhuriyet.edu.tr, https://orcid.org/0000-0002-8535-6246.

** Öğr. Görevlisi, Sivas Cumhuriyet Üniversitesi, Sivas Meslek Yüksekokulu, El Sanatları Bölümü, fatihcakmaktepe@cumhuriyet.edu.tr, https://orcid.org/0000-0002-9741-284X. 


\section{Giriş}

İnsanoğlu hayatını sürdürürken çevresinde bulunan hammaddeleri kendi ihtiyaçlarını karşılayacak şekilde işlemiştir. Koyunlarından elde ettiği yünü kendine ev, giysi, yatak, örtü, çuval ve taşıma gereci gibi daha birçok farklı amaca hizmet aracı olarak üretmiştir. Bunu yaparken de içinde taşıdığı değerler bütününü sanatsal olarak el sanatları eserlerine yansıtmıştır. Günlük kullanım için yapılan herhangi bir eşya dahi sanat eseri niteliği kazanmıştır. Anadolu da üretilen dokuma türlerinden birisi olan çarpana, diğer dokuma türlerine göre alan açısından çok daha ince olmasına rağmen desensiz olarak üretilmemiştir. Bunun tam aksine büyük bir kültürel zevkle birbirinden güzel oldukça zengin motiflerle bezendiği görülmektedir. Gerek konargöçer, gerekse yerleşik Türkler için de özellikle taşıma ve bağlama aracı olarak çarpana dokumalarının ayrı bir önemi bulunmaktadır. Çarpana dokumalarını çok farklı malzemelerden oluşturdukları çarpana levhalarından faydalanarak dokumuşlardır.

Deve derisi ve ahşap gibi malzemelerden yapılan 3-4-6-8 köşeli, 5x5cm ebadındaki levhalara çarpana denir. Bu levhalarda renkli çözgü iplikleri ile atkı ipliklerinin birleştirilerek farklı genişliklerde yapılan şeritlere çarpana dokuma denmektedir (Erbek, 1980:7).

Kolan dokumalar, kullanılan araca ve tekniğe göre kartsız ya da kartlı olarak iki türde dokunmaktadır. Kartıı olan dokuma daha çok çarpana olarak bilinmektedir (Sarıoğlu, 2005:14). Yün ya da yün-kıl karışımı ile 3-7 cm eninde dokunmuş ince uzun yassı şerit dokumalara kolan denmektedir (Barışta, 2005:221).

Kolan ve çarpana dokumaları görünüm olarak birbirine benzemekle birlikte dokuma tekniği ve dokuma araçları açısından farklılıklar barındırmaktadır (Sarıoğlu, 2005:14). Kolan dokumalar genellikle evin dışında yere çakılan kazıklar arasına gerilen ipliklerle yapılmaktadır. Çarpana ise mekândan bağımsız olarak çözgü iplerini gerdirecek bir ortamda yapılabilmektedir. Çarpana dokumalar kolan dokumalara göre genellikle daha ince olarak yapılmaktadır. Her iki dokuma kullanımında ve isimlendirilmesinde net bir ayırım yoktur. Farklı yörelerde eni dar boyu uzun çoğunlukla bağlama amacıyla kullanılan dokumalar kolan ve çarpana olarak ifade edilmektedir. 
Çarpana dokuma; Tarihi çok eskilere dayanan çarpana dokumalarının yapımında kullanılan levhaların bölgesel olarak malzeme ve şekillerinde farklılıklar bulunmaktadır. Çarpananın dokucusunun hayatındaki yerini mezarlardan çıkan çarpana araçları ispatlayan bir göstergedir. Çarpana dokuma aracı olarak kullanılan levhalarda at, deve veya geyik derisinden, fildişine, balık derisinden kemik veya parşömene, kalın mukavvadan Fransız oyun kağıdına, ahşaptan plastiğe kadar birçok malzemeden yararlanılmıştır. Çarpana dokumacılığındaki levha malzemesinin çeşitliliği kadar dokumayı desenlendirme olanağı da çok geniştir (Kosswig, 1970:88). İnsanoğlu çevresinde bulduğu malzemeyi kendi ihtiyacını karşılayacak şekilde alet geliştirerek değişik tekniklerle hammaddeye hayat vermişlerdir.

Çarpana dokumada kullanılan levhalar; kalınlığı 1-3 mm pürüzsüz yüzeyli deri, ahşap, fildişi, karton, iskambil kartları gibi sert olan malzemelerden yapılmaktadır. Çarpana levhalarının şekilleri; üçgen, kare, altıgen ve sekizgen olabilmektedir. Her bir köşede bir delik bulunur ve yapılması planlanan desene göre çözgü ipliği bu delikten geçirilmektedir (Aytaç, 1982:22).

Çarpana dokumalarının geçmişine baktığımız zaman kurgan eserlerinden olan eyer takımlarının üzerinde bulunan kuşak, kolan ve kordonlardan ne kadar köklü bir sanat olduğu görülmektedir (Arslan, 2014:124). Kullanım yeri farklı olsa da her bir çarpana motiflerle bezelidir.

Birkaç farklı şekilde olan çarpana levhalarından Anadolu'da kare olanlar daha yaygın olarak kullanıldıkları görülmektedir. Çözgü yüzlü bir dokuma olan çarpana, levha üzerinde bulunan deliklerden uygulanacak desene göre çözgü iplikleri geçirilerek yapılmaktadır (Atlıhan, 2020:192). Konar-göçer yaşayan Türklerin hayatında bağlama gereci olarak kullanılan kolan ve çarpananın daha ayrı bir öneme sahip olduğu bilinmektedir.

Bir topluluğun maddi ve manevi aynasına sanat denebilir. Hun kurganlarından çıkan fevkalade güzel halı, kilim, cicim, keçe ve kolan dokuma örnekleri tekniğin ne düzeyde olduğunu gösteren değerli eserlerdir. Hunlarda yund denen çadırı bağlamak ve süslemek için kolan kullanıldığı bilinmektedir (Diyarbekirli, 1972:108).

Çarpana dokumalar; giyim eşyası niteliğiyle kadın ve erkeklerde kuşak olarak, çadırın her türlü bağlanmasında, bebeklerin güvenliği ve taşınması için beşik, kundak ve çocuk bağı olarak, 
farklı şekillerde taşıma aracı olarak ve bunun yanında barutluk, fişek çantası, kılıç askısı, Kur'an bağı, terlik ve takunya bantı olarak kullanılmaktadır (Erbek, 1980:8-11).

Kolanlar taşıma araçlarında, hayvanların koşum takımları ve süslemelerinde kadın giyimi gibi birçok alanda çeşitli amaçlara hizmet etmiştir. Günümüzde ise daha çoğunlukla süsleme unsuru olarak kullanılmaktadır (Akpınarlı vd., 2012:53).

Çarpana dokuma işleminde hazırlanan çözgü ipliklerinin bir ucu dokuyucunun beline bağlanır diğer ucu bir yere sabitlenerek dokuma gerçekleştirilir. Çarpana dokumada düz dizgi, orta simetri, ayna simetri ve grup simetri gibi sistemlerle iplikler çarpana deliklerinden geçirilerek dokumalar üretilmektedir (Aytaç, 2010:192).

Çarpana dokuma tekniği basit bir çözgü aracından fazla bir şey gerektirmeden yapılabilmektedir. Çözgüleri gerdiren bir sistemle farklı yerlerde dokuma işlemi kolayca gerçekleştirilir. Çarpana için ipliklerin düzenlenme şekline ve çarpana kartlarının yerleştirilmesi ve hareketine göre; Fitilli ve saç örgüsü, tel örgü ve pirinç, susma ve daldırma, strüktür teknikleri ile dokuma işlemi gerçekleştirilir (Kosswig, 1970:85-86).

Sivas, Anadolu'nun birçok bölgesindeki gibi dokumacılıkla yoğrulmuş topraklardan biridir. Dokuma kültürü zengin bu şehirde çarpana dokumalarına rastlamak şaşırtıcı değildir. Günümüzde çarpana dokumacılığı az da olsa birkaç eğitim kurumunda devam etmektedir. Geçmişin hatıralarını günümüze taşıyan örneklere müze bünyesinde ulaşılmaktadır (Görsel 1). Bu çalışmada Sivas Arkeoloji Müzesi depolarında bulunan çarpanalardan esinlenerek yeni tasarımların yapılması amaçlanmıştır. Bu doğrultuda çarpana ve kolanlarla ilgili makaleler taranmıştır. Çarpanaların dokuma tekniklerini daha iyi görebilmek için büyüteçle bakılmış ve yakın çekimle fotoğraflanmıştır. Evnaterleri incelenmiş ve teknik özellikleri belgelenmiştir. Fotoğraflardan yaralanarak çarpanaların motif çizimleri gerçekleştirilmiştir. Motiflerden esinlenilerek yeni çarpanalar dokunmuştur.

\section{Çarpanalarda Uygulanan Dokuma Tekniği}

Anadolu çarpanaları farklı tekniklerle dokunmaktadır. Burada kartı kendi ekseni etrafında döndürme sistemi ile dokunmuştur. Kare ve dört delik sistemine sahip çarpana kartlar kullanılmıştır. Müze bünyesinde bulunan çarpanaların motifleri çizildikten sonra (Görsel 2-10) kaç 
adet kart kullanılacağı tespit edilmiştir. Çarpana kenarında yer alan ve bütün çarpana boyunca aynı renk olan çizgiler için sağ ve solda bulunan iki ya da dört kartların bütün deliklerinden aynı renk iplik geçirilmiştir. Kenar süslemede ise farklı iki renk daha kullanılmış ve bir hat olarak dokuma boyunca devam ettirilmiştir. Buradaki çarpanaların orta kısmında yer alan motif ve zemin olarak iki renkli iplik kullanılmıştır. Bu nedenle ortadaki kartların A-B deliklerinden aynı renk, C-D deliklerinden ise diğer renk iplik geçirilmiştir. Desen takibi yapılarak daima çalışan renk üstte motif oluşturacak şekilde bazen kart kendi etrafında döndürülerek ileri doğru hareket ettirilmektedir. Böylece dokuma boyunca istendiği kadar motif değiştirme şansı elde edilmektedir. Dokuma işleminde temel mantık motif oluşturacak iplerin hep üstte olacak şekilde düzenlenmiş olmasıdır. Bu dokuma tekniği ile bir çarpana üzerinde birçok farklı motif uygulanabilmiştir.

Görsel 1 de yer alan çarpana dokumanın dokuma işlemi şu şekildedir; toplam 23 kart kullanılmıştır. Her iki kenardaki ilk kartın bütün deliklerinden siyah geçirilmektedir. İkinci, üçüncü, yirmi bir ve yirmi ikinci kartların A-B deliklerinden sarı, C-D deliklerinden ise turuncu renkli iplik geçirilmektedir. Ortada kalan çarpana kartlarının hepsinin A-B deliklerinden siyah, C-D deliklerinden krem iplik geçirilmektedir. Dokuma yüzeyinde görünecek renge göre kartların pozisyonları ayarlanarak ileri doğru döndürülerek dokunmaktadır. Dokumanın yüzü ile tersinde zemin ve motif renkleri yer değiştirmektedir. Her iki yüzü de motiflerle bezelidir.

\section{Sivas Arkeoloji Müzesi'nde Envantere Kayıtlı Çarpana Örnekleri}

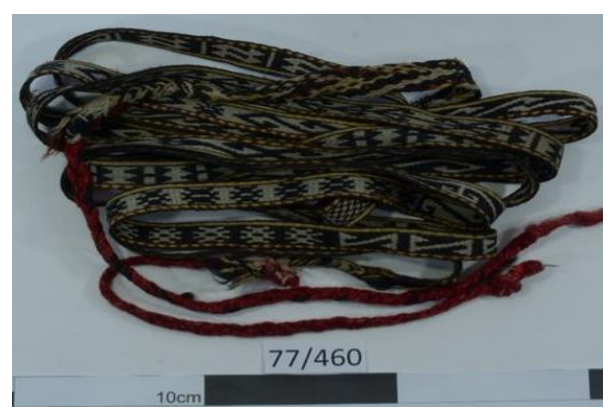

Görsel 1. 77/460 Envanter Numaralı Çarpana, Çarpana Dokuma, Sivas Arkeoloji Müzesi 
SDÜ ART-E

Güzel Sanatlar Fakültesi Sanat Dergisi

Aralık'21 Cilt:14 Sayı:28 ISSN 1308-2698

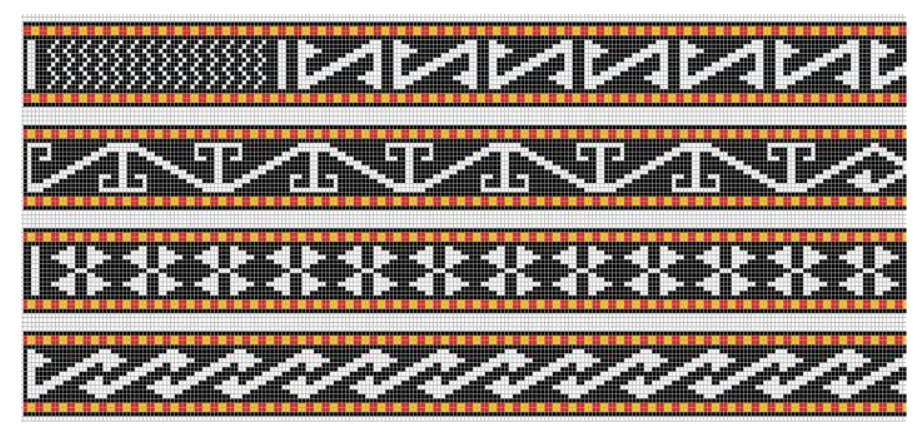

Görsel 2. 77/460 Envanter Numaralı Çarpana Çizimi, 2021

Örnek No: 77/460

Kart Sayısı: 23

Çarpana Boyu: 512cm, Eni: $2 \mathrm{~cm}$

Yapılış Tarihi: 19.yy.

Yapılış Amacı: Kuşak

Kullanılan iplik Cinsi: Çözgü-Atkı yün

Renk Dağılımı: zemin; krem/siyah, motif; siyah/krem, kenar süsleme; sarı-turuncu, siyah

Kompozisyon: Bele bağlamak amacıyla saç örgüsü tekniğinde kuşak olarak dokunmuştur. Krem zemin üstünde siyah renkli çengel, çakmak, pıtrak, çiçek, koçboynuzu, elibelinde gibi birçok farklı motifin değişerek sıralanması ile oluşturulmuştur. Motifin her iki yanı sarı-turuncu ve siyah bir hat dokuma boyunca devam etmektedir. Çarpana kartlarının hepsi ileri doğru döndürülmektedir. Çarpananın her iki ucu da tek bir saç örgüsü ile bitirilmiştir.

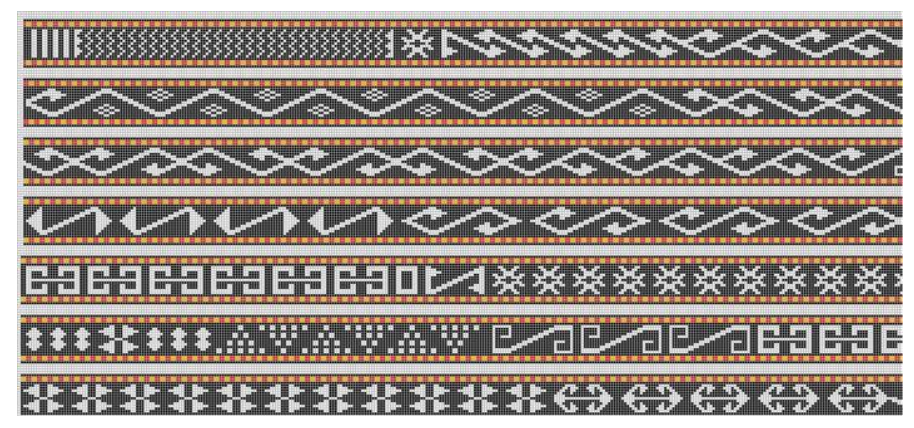

Görsel 3.2005/27 Envanter Numaralı Çarpana Çizimi, 2021 
Envanter No: 2005/27

Kart Sayısı: 18

Çarpana Boyu: $690 \mathrm{~cm}$, Eni: 1,5cm

Yapılış Tarihi: 20.yy.

Yapılış Amacl:-

Kullanılan iplik Cinsi: Çözgü-atkı yün

Renk Dağılımı: zemin; siyah/krem, motif; krem/, kenar süsleme; sarı-kırmızı

Kompozisyon: Çarpana saç örgüsü tekniğinde dokunmuştur. Dokuma siyah zemin üstünde krem renkli; çengel, çakmak, dal-çiçek, koçboynuzu, bukağı, muska, yıldız, elibelinde, pıtrak, göz gibi birçok farklı motif ile bezelidir. Kenarlar ise sarı kırmızı renklerin sıralanması ile bir hat oluşturulmuştur. Dokumanın uç kısmında "OL" harfleri yer almaktadır. Çarpana kartlarının hepsi ileri doğru döndürülmektedir.

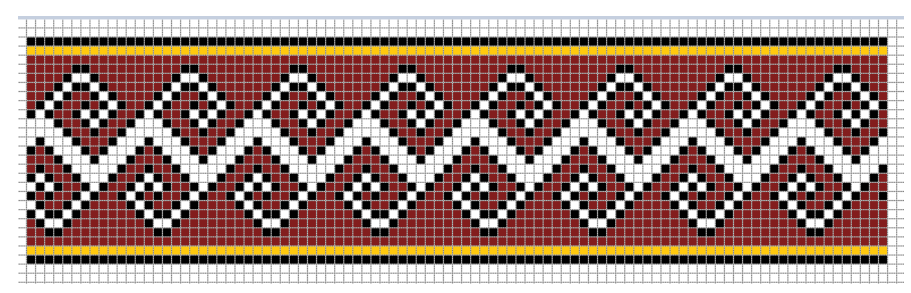

Görsel 4. 2005/28 envanter numaralı çarpana çizimi, 2021

Envanter No: $2005 / 28$

Kart Sayısı: 19

Çarpana Boyu: $428 \mathrm{~cm}$, Eni: 1,5cm

Yapılış Tarihi: 20.yy.

Yapılış Amacı: -

Kullanılan iplik Cinsi: Çözgü - atkı; yün

Renk Dağılımı: zemin; kırmızı, motif; krem, kenar süsleme; sarı, siyah ve yeşil 
Kompozisyon: Dokuma kırmızı zemin üstüne siyah konturla çevrili krem renkli kıvrımlı dal motifi ile bezelidir. Kenarı sarı, siyah ve yeşil bir hat ile dokunmuştur. Fitilli dokuma tekniğiyle yapılmıştır. Çarpana kartlarının hepsi ileri doğru döndürülmektedir.

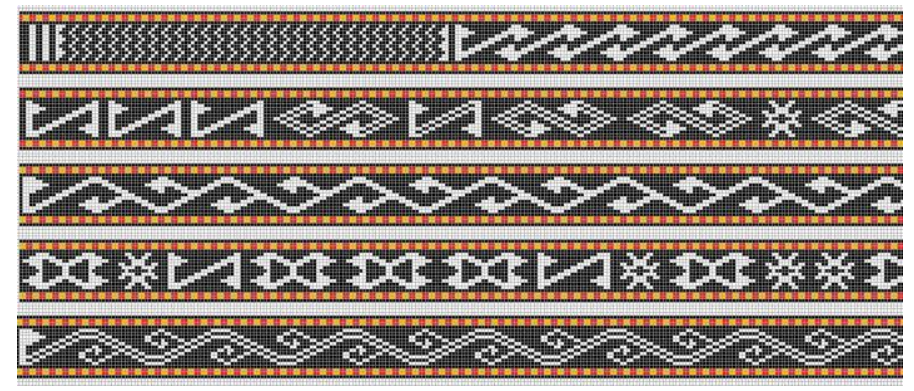

Görsel 5. 2005/29 Envanter Numaralı Çarpana Çizimi, 2021

Envanter No: 2005/29

Kart Sayısı: 19

Çarpana Boyu: $608 \mathrm{~cm}$, Eni:1,5cm

Yapılış Tarihi: 20.yy.

Yapılış Amacı: -

Kullanılan iplik Cinsi: çözgü - atkı; yün

Renk Dağılımı: zemin; siyah/krem, motif; krem/siyah, kenar süsleme; kırmızı-sarı

Kompozisyon: Siyah zemin üzerinde çengel, çakmak, dal-çiçek, hayat ağacı, pıtrak gibi birçok motifle bezelidir. Motiflerin kenarında ise sarı-kırmızı renklerin değişimi ile bir hat oluşturulmuştur. Teknik olarak saç örgüsü tekniği ile dokunmuştur. Çarpana kartlarının hepsi ileri doğru döndürülmektedir. 


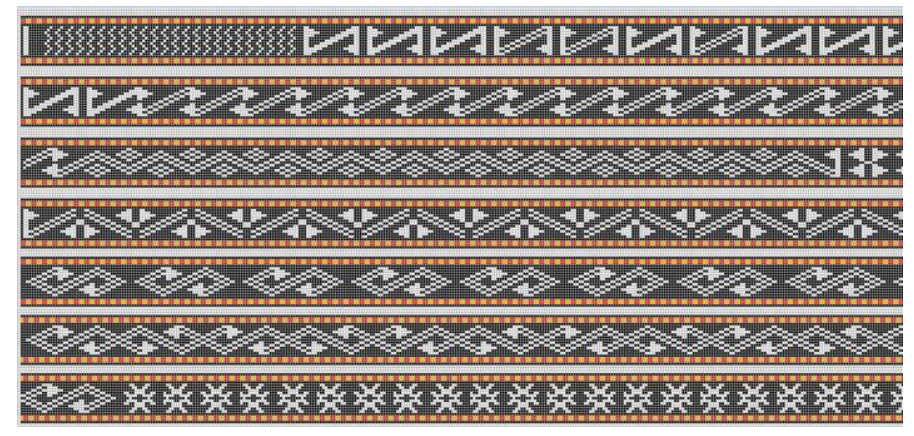

Görsel 6. 2005/30 Envanter Numaralı Çarpana Çizimi, 2021

Örnek No: 2005/30

Kart Sayısı: 19

Çarpana Boyu: $730 \mathrm{~cm}$, Eni: 1,5cm

Yapılış Tarihi: 20.yy

Yapılış Amacl: -

Kullanılan iplik Cinsi: çözgü - atkı; yün

Renk Dağılımı: zemin; siyah/krem, motif; krem/siyah, kenar süsleme; sarı- kırmızı

Kompozisyon: Çarpana saç örgüsü tekniği ile gerçekleştirilmiştir. Siyah zemin üstüne krem renkli çengel, çakmak, dal-çiçek, bukağı, pıtrak, sandıklı motifleri ile bezelidir. Kenarlar ise kırmızı ve sarı rengin dönüşerek oluşturduğu hat ve siyah renkle çizgi şeklinde dokunmuştur. Dokumanın bir ucunda "A ELi”" yazmaktadır. Çarpana kartlarının hepsi ileri doğru döndürülmektedir. Çarpananın her iki ucu saç örgüsü ile örülüdür.

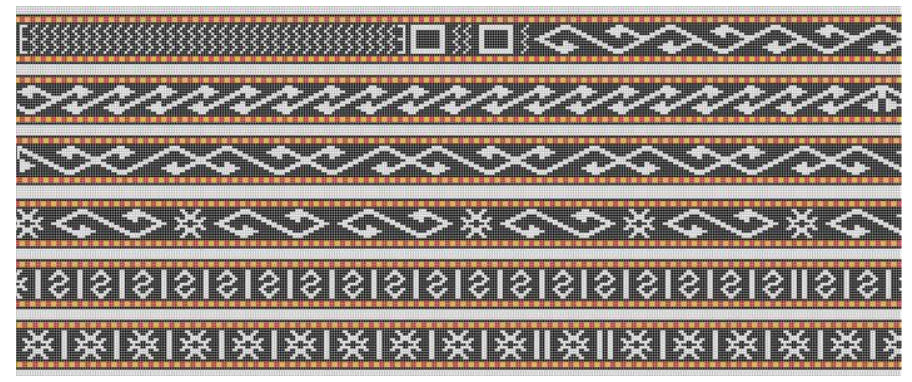

Görsel 7. 2005/31 Envanter Numaralı Çarpana Çizimi, 2021 
Envanter No: 2005/31

Kart Sayısı: 20

Çarpana Boyu: $750 \mathrm{~cm}$, Eni: 1,3cm

Yapılış Tarihi: 20.yy.

Yapılış Amacı: -

Kullanılan iplik Cinsi: çözgü - atkı; yün

Renk Dağılımı: zemin; siyah/krem, motif; krem/siyah, kenar süsleme; sarı- kırmızı

Kompozisyon: Çarpananın kenarı fitilli ortası saç örgüsü tekniğinde dokunmuştur. Siyah zemin üstünde çengel, çakmak, dal-çiçek, bukağı, çiçek ve pıtrak gibi motiflerle bezeli olarak dokunmuştur. Dokumanın her iki kenarı bordo rengi ile çizgi halinde şeritler mevcuttur. Çarpana kartlarının hepsi ileri doğru döndürülmektedir. Çarpanın uçları düğümlenerek iplikler açık bırakılmıştır.

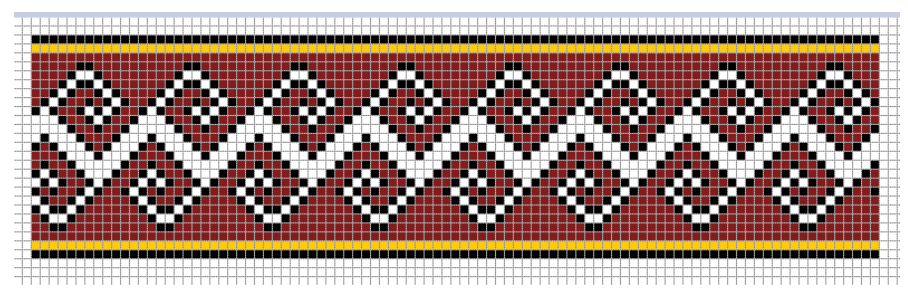

Görsel 8. 2005/32 Envanter Numaralı Çarpana Çizimi, 2021

Envanter No: 2005/32

Kart Sayısı: 28

Çarpana Boyu: $330 \mathrm{~cm}$, Eni: $1 \mathrm{~cm}$

Yapılış Tarihi: 20.yy.

Yapılış Amacı: -

Kullanılan iplik Cinsi: Çözgü-atkı yün

Renk Dağılımı: zemin; bordo, motif; krem, kenar süsleme; sarı 
Kompozisyon: Çarpana fitilli dokuma tekniğinde yapılmıştır. Bordo zemin üzerine krem kıvrım motifi dokuma boyunca devam etmektedir. Kıvrım motifinin her iki kenarında sarı ve siyah çizgi bulunmaktadır. Çarpana kartlarının hepsi ileri doğru döndürülmektedir. Dokumanın her iki ucu ve orta kısmı yıpranmış bir haldedir.

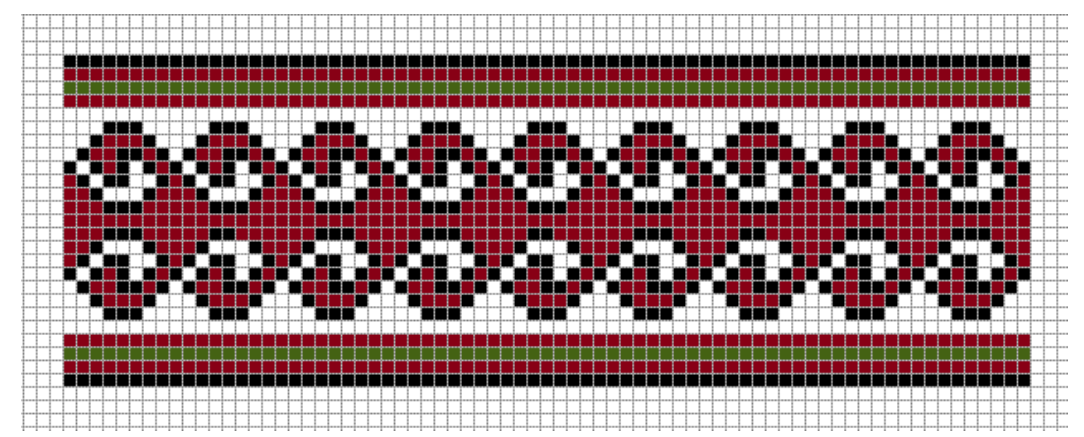

Görsel 9.2005/33 Envanter Numaralı Çarpana Çizimi, 2021

Envanter No: 2005/33

Kart Sayısı: 32

Çarpana Boyu: $575 \mathrm{~cm}$, Eni: 3,4cm

Yapılış Tarihi: 20.yy

Yapılış Amacı: -

Kullanılan iplik Cinsi: Atkı-çözgü tamamı yün

Renk Dağılımı: zemin; bordo, motif; krem, kenar süsleme; sarı

Kompozisyon: Çarpananın kenarları fitilli ortası saç örgüsü tekniği ile yapılmıştır. Çarpana kartlarının hepsi ileri doğru döndürülmektedir. Dokuma orta alanda krem zemin üstünde siyah kontörle çerçevelenmiş bordo renkli elibelinde motifinin tekrarı ile dokuma boyunca devam etmiştir. Kenarlar ise bordo, yeşil ve siyah renklerle şeritler oluşturulmuştur. Dokumanın orta kısmına üç düğme dikilmiş, her iki ucunda da altı adet uzun püsküller yer almaktadır. 


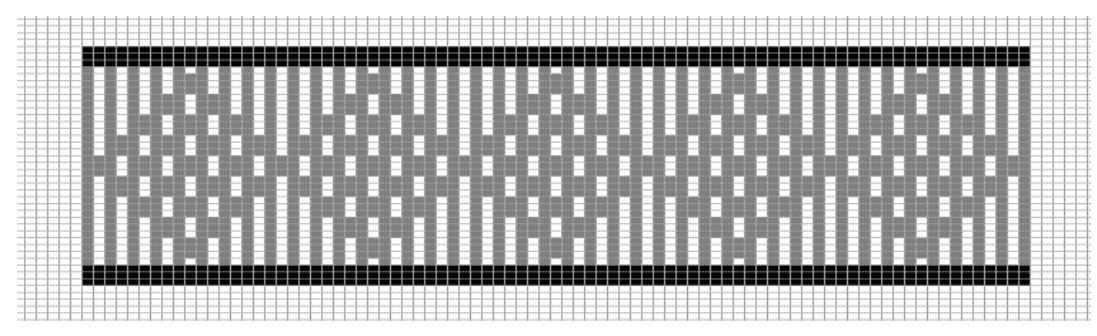

Görsel 10.963 envanter numaralı çarpana çizimi, 2021.

Envanter No: 963

Kart Sayısı: 35

Çarpana Boyu: 134,5cm, Eni:4,5cm

Yapılış Tarihi: -

Yapılış Amacı: Kuşak

Kullanılan iplik Cinsi: çözgü; pamuk-sim, atkı; pamuk

Renk Dağılımı: zemin; lacivert/gümüş rengi, motif; gümüş rengi/lacivert

Kompozisyon: Dokuma lacivert renkli pamuk ve gümüş sim (gelin teli) çözgü ile lacivert renkli atkı ile dokunmuştur. Kenar çözgüleri pamuk iplik ile orta kısmı ise sim ile hazırlanmıştır. Üzerinde baklava dilimi şeklinde göz motifi işlenmiştir. Çarpana kartlarının hepsi ileri doğru döndürülmektedir. Püsküller gruplandırılarak beş adet olarak toplanmış uçları açıktır. Anadolu çarpana dokuma geleneğinden oldukça farklıdır. Topkapı sarayında bulunan çarpana dokumaları ile benzerlikleri dikkat çekmektedir. 


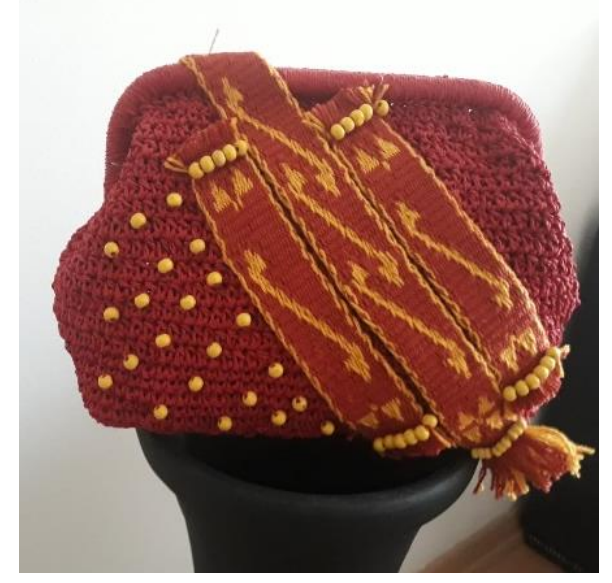

Görsel 11. Çarpanalı Örme Çanta, 2021, Çarpana Dokuma.

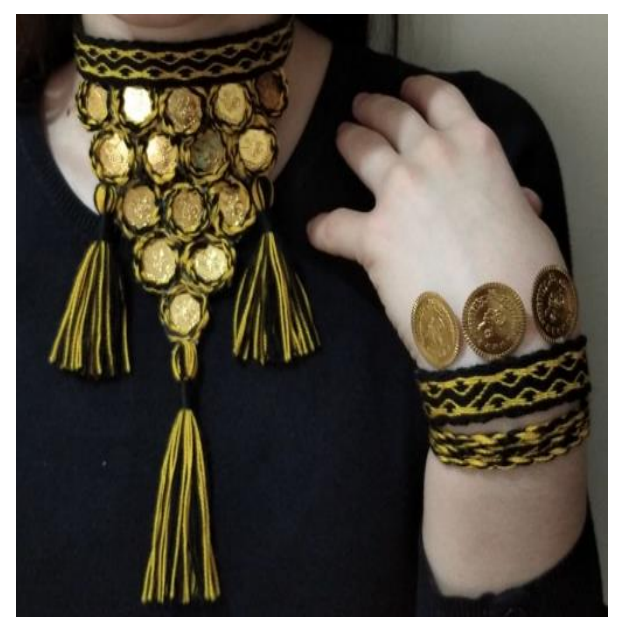

Görsel 12. Çarpana Takı (kolye ve bileklik), 2021, Çarpana Dokuma.

\section{Sonuç}

Sivas çarpanalarında görülen bir motifi, Anadolu'nun herhangi bir yerinde çarpana ya da bir kilim üzerinde görmek mümkündür. Bu durum kültür birlikteliğinin ispatı niteliğindedir. Genellikle ince bant şeklinde yapılan çarpana dokumalar kilimlerin küçük birer örneği niteliğindedir. Anadolu kilim ve çarpana motiflerinin benzerlikleri dikkate değer niteliktedir. Zengin bir desenlendirme özelliğine sahip olan çarpanalar uzunluklarından bağımsız olarak bazen sadece bir motif ile bezeli iken bazen de birçok motifle süslenmiştir. Buradaki çarpanalarda da bazen bir motifin birkaç farklı şekilde uygulanışı görülmektedir. 
Çalışmaya konu olan dokuz adet eserlerden biri satın alınma diğerleri bağış yoluyla müzeye kazandırılmıştır. Çarpanalarda kullanılan malzeme, renk ve motifler birbirleri ile benzerlik göstermektedir. Yalnızca 963 envanter numaralı çarpana, malzeme renk ve motif olarak diğerlerinden farklı görünmektedir.

Renkler dokumalar için en önemli özelliklerdendir. İncelenen çarpana dokumalarında krem ve siyah renkler hakim durumdadır. Bunun yanı sıra bordo, turuncu, sarı ve yeşil renklerine de yer verilmiştir.

Çarpana levhaları geçmişte tamamen doğal hammadden yapılırken günümüzde ise ahşap ve mukavvanın yanında plastik malzemelerden yapıldığı bilinmektedir. Yeniden dokunan Görsel.11-12' de görünen çarpanaların yapımında da plastik kartlardan faydalanıımıştır.

Çarpana dokumaların geçmişte genellikle ihtiyaca yönelik olarak üretildiği bilinmektedir. Günümüzde malzemenin daha fazla çeşitlenmiş olmasıyla üretim dekoratif amaca yönelik olarak şekillenmiştir. Bu ürünler zaman zaman şık bir kolye, kıyafet, aksesuar ya da bir kitap ayıracı olarak karşımıza çıkmaktadır. Çalışmada yer alan ilk sekiz çarpanadan esinlenilerek saç örgüsü ve fitilli teknikte beş adet tasarım yapılmıştır. Bordo, turuncu, sarı, beyaz, siyah ve kahverengi renklerde pamuklu iplikle dokunmuştur.

\section{Teşekkür}

Çalışma yapmamıza olanak tanıyan ve her türlü desteği sağlayan Sivas Arkeoloji Müzesi Müdür ve personeline teşekkür ederiz.

\section{Kaynakça}

Akpınarlı, H.F. vd. (2012). Şanlıurfa El Sanatları ve Sözlü Kültür Malzemeleri. Ankara: Şurkav Yayınları.

Arslan, H. Y. (2014). "Kolan Dokumanın Giysi Tasarımında Kullanılması", Motif Akademi Halkbilim Dergisi, Sayı 1, s.123-139.

Atlıhan, Ş. (2020). "Çarpana Dokumaların Sanatsal Özellikleri”, Folklor Akademi Dergisi. Cilt 3, Sayı 4, s. 190-201.

Aytaç, A. (2010). "Kırgızistan'da Çarpana ve Kolon Dokumacılığından Örnekler", Milli Folklor, Yıl 22, Sayı 87, s.191-195. 
Aytaç, Ç. (1982). El Dokumacılığı Temel Ders Kitabı, M. E. B. Mesleki ve Teknik Eğitim Kitapları, İstanbul.

Barışta, H.Ö. (2005). Türkiye Cumhuriyeti Dönemi Halk Plastik Sanatları, T.C. Kültür ve Turizm Bakanlığı, Ankara.

Diyarbekirli, N. (1972). Hun Sanatı, Milli Eğitim Bakanlığı Kültür Yayınları.

Erbek, G. (1980). “Çarpana Dokumaları”, Türkiyemiz. Sayı:30. s.7-11.

Kosswig L. (1970). Çarpanacılık ve Istanbul Topkapı Saray Müzesinde Bulunan Çarpana Dokumaları. Ankara: Türk Tarihi Kurumu Basımevi.

Sarıoğlu, H.vd.(2005) Dokuma-I Çarpanalı Dokumalar, YA-PA Yayınları, İstanbul.

\section{Görsel Kaynaklar}

Görseller kişisel arşive aittir. 